\title{
Pattern of Non-Hodgkin Lymphoma in a Tertiary Care Center in Northeast India Using Morphology and Immunohistochemistry
}

Sir,

Lymphoma is a neoplasm with clonal expansion of lymphoid cells that share the histologic pattern and immunohistochemistry (IHC) of their normal counterpart. They can arise in lymph nodes or in extranodal sites. There is a marked geographic variation in lymphoma. It is higher in the developed Western world and lower in Asia and Africa, except endemic Burkitt lymphoma and some T-cell lymphomas. ${ }^{[1]} \mathrm{A}$ limited number of studies on non-Hodgkin lymphoma (NHL) have been carried out in Northeast India. The current study was carried out to diagnose cases of NHL using both morphology and IHC. A prospective study over a 18-month duration was carried out from July 2016 to December 2017 to study the pattern and prevalence of lymphoma cases presenting to our tertiary care center.

Sections from the paraffin-embedded tissues were stained using hematoxylin and eosin stain. Morphology of the cells was studied, and the necessary immunohistochemical markers were advised. The basic panel for lymphoma at our institute is CD45, CD20, and CD3, along with CD30, CD15, ALK, EMA, MUM1, BCl2, BCl6, CD10, CD5, CD23, Cyclin D1, TdT, and Ki67. Diagnosis was made after morphological and immunohistochemical correlation. Biochemical and radiological findings were recorded.

A total of 151 cases were studied, and NHL comprised $86 \%$ (130 cases) of the total cases. Of the total NHL cases, $76 \%$ (95 cases) were B-cell NHL and $24 \%$ (30 cases) were T-cell NHL [Table 1]. In a study by Boffetta et al., a higher proportion of B-cell NHL such as diffuse large B-cell lymphoma (DLBCL) and follicular lymphoma is seen in America compared to the increased prevalence of T-cell NHL in Asian countries. ${ }^{[2]}$ Asians have a higher incidence of T-cell lymphoma compared to the Western population, probably due to a lesser number of certain B-cell lymphomas. ${ }^{[3]}$ In India, a study by Naresh et al. found B-cell lymphoma to comprise $79.1 \%$ of the NHLs, whereas T-cell lymphomas formed 16.2\% of the total. ${ }^{[4]}$
Among 130 NHL cases, 94 (72\%) were male and 36 (28\%) were female in our study.

NHLs have a varied age distribution. It is a disease most common in the middle-aged and elderly. Lymphoblastic lymphoma is common in children and adolescents (three cases). In our study, we observed that DLBCL had a varied age range from 5 years to 93 years, while PTCL was common in the middle-aged population. Burkitt lymphoma is common in children. The median age for NHL was 53.5 years. The median age for T-cell NHL was found to be 44 years, and that for B-cell NHL, it was 55 years [Figures 1 and 2].

Among NHLs, according to the International non-Hodgkin's Lymphoma Study Group Series, the most common was DLBCL with $31 \%$ cases, followed by $22 \%$ of follicular lymphoma. All types of T-cell processes, including natural killer cell disorders, made up only $12 \%$ of the cases. ${ }^{[5]}$ According to Naresh et al., DLBCL was the most common subtype (34\% of all NHLs) followed by follicular lymphoma. ${ }^{[4]}$ In our study, five cases of NHL could not be subclassified as they were lost to follow-up. B-cell type accounted for 95 cases, whereas 30 cases were of T-cell subtype. DLBCL was the most common subtype of B-cell NHL, comprising 76 cases $(80 \%)$, followed by follicular lymphoma which comprised of 6 cases (7\%). Among

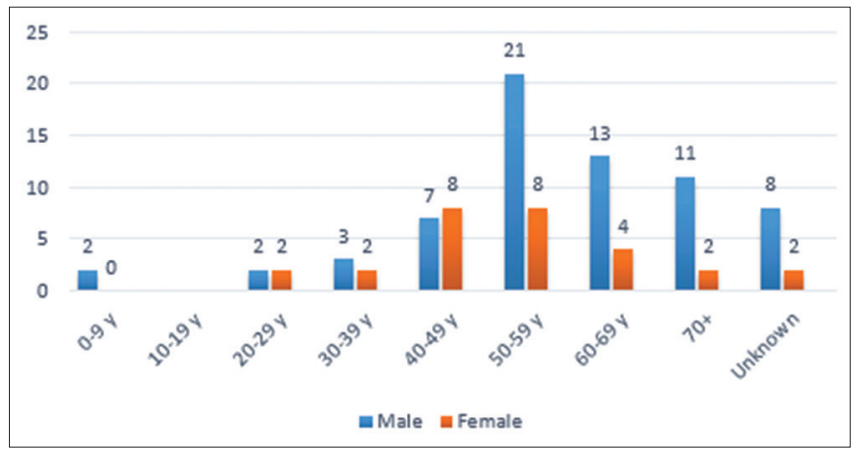

Figure 1: Age distribution of B-cell non-Hodgkin lymphoma

\begin{tabular}{|c|c|c|c|c|c|c|c|c|c|c|}
\hline \multicolumn{11}{|c|}{ Table 1: Age and sex distribution of NHL } \\
\hline Age in yrs & $0-9$ & 10-19 & $20-29$ & 30-39 & $40-49$ & $50-59$ & $60-69$ & $70+$ & Unknown age & Total \\
\hline \multicolumn{11}{|c|}{ B cell non hodgkin lymphoma } \\
\hline B cell NHL Male & 2 & & 2 & 3 & 7 & 21 & 13 & 11 & 8 & 67 \\
\hline B cell NHL Female & & & 2 & 2 & 8 & 8 & 4 & 2 & 2 & 28 \\
\hline Total & 2 & & 4 & 5 & 15 & 29 & 17 & 13 & 10 & 95 \\
\hline \multicolumn{11}{|c|}{ T cell non hodgkin lymphoma } \\
\hline $\mathrm{T}$ cell NHL M & 1 & 5 & 2 & 2 & 4 & 4 & 6 & & & 24 \\
\hline T cell NHL F & 1 & & & 1 & 1 & 1 & & 2 & & 6 \\
\hline Total & 2 & 5 & 2 & 3 & 5 & 5 & 6 & 2 & & 30 \\
\hline
\end{tabular}


Table 2: Extranodal disease

\begin{tabular}{llr}
\hline Subtype & Site of extranodal lymphoma & \% \\
\hline DLBCL & Testis, tonsil, base of tongue, stomach, parotid, right iliac fossa, caecum, ocular & 58 \\
Follicular lymphoma & Parotid, ileocaecal region & 7 \\
Mantle cell lymphoma & Nasopharynx, rectum & 7 \\
Marginal zone lymphoma & Parotid & 3 \\
Burkitt lymphoma & Lower gingivobuccal sulcus & 3 \\
TCRBCL & Cervix & 3 \\
Primary cns lymphoma & CNS & 3 \\
PTCL (nos) & Nasopharynx, rectosigmoid, palate \\
Extranodal nk/t cell lymphoma & Hard palate \\
Total & $31(20.5 \%)$ \\
\hline
\end{tabular}

DLBCL: Diffuse large B-cell lymphoma

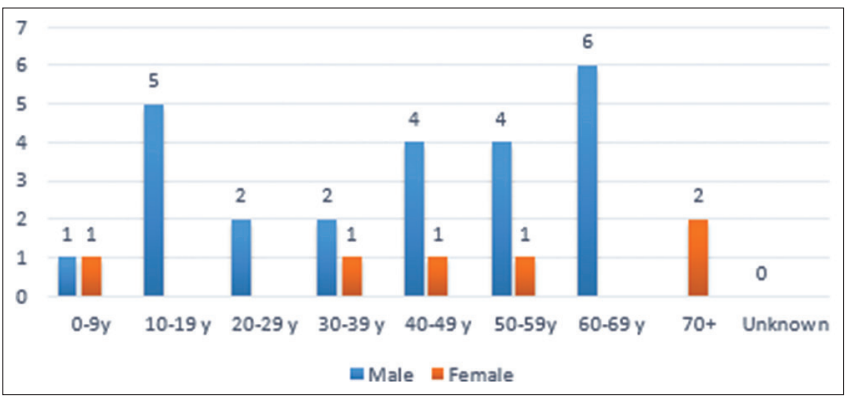

Figure 2: Age distribution of T-cell non-Hodgkin lymphoma

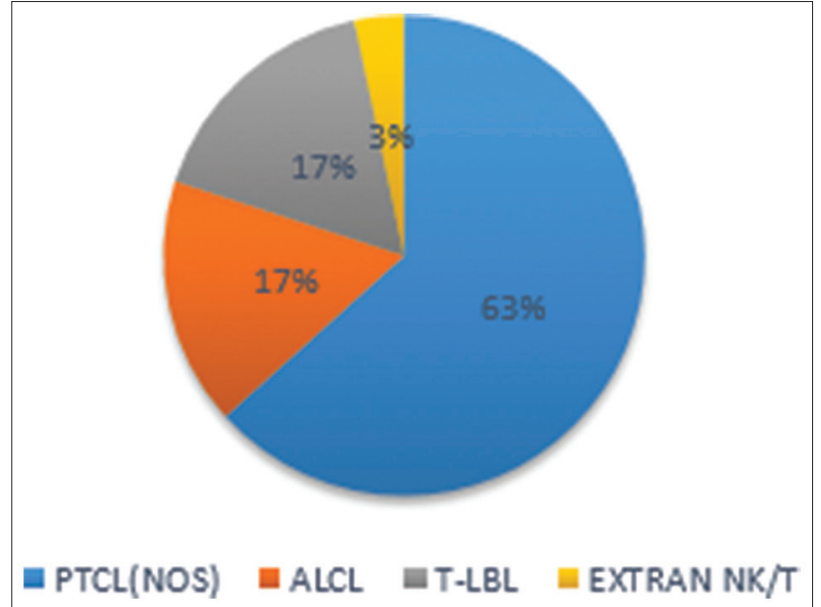

Figure 4: Subtypes of T-cell non-Hodgkin lymphoma

T-cell NHLs, peripheral T-cell Lymphoma (PTCL [NOS]) was the most common with 19 cases $(63 \%)$ followed by anaplastic large cell lymphoma (17\%) and T-lymphoblastic lymphoma (17\%) [Figures 3 and 4].

Nodal presentation is common; however, 31 cases $(20.5 \%)$ were found to have a primarily extranodal presentation [Table 2 and Figure 5]. Eighteen cases were of extranodal DLBCL subtype, two cases were mantle cell lymphoma, two were follicular lymphoma, and one was T-cell-rich B-cell lymphoma. One case of marginal zone lymphoma was from the parotid gland. One case of Burkitt Lymphoma was also detected in the gingivobuccal sulcus. Five cases

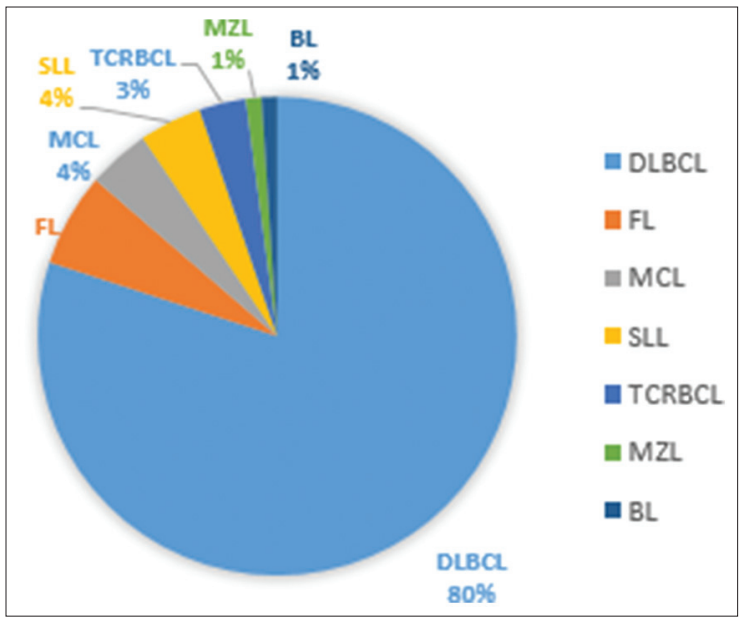

Figure 3: Subtypes of B-cell non-Hodgkin lymphoma

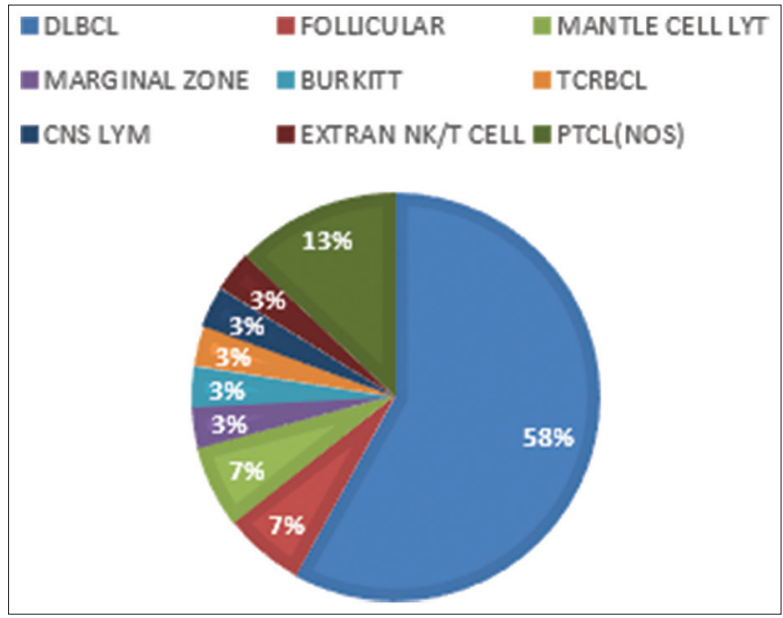

Figure 5: Extranodal lymphoma

were extranodal T-cell NHL, PTCL (NOS) subtype. The gastrointestinal tract was found to be the most common site of extranodal disease (11 cases) followed by testis and tonsils (four each).

Cyclophosphamide, doxorubicin, vincristine, and prednisone regimen with or without rituximab is used in the management of NHLs in our setup. 


\section{Acknowledgment}

The authors are grateful to the Director, Dr. B. Borooah Cancer Institute, for allowing us to publish this article.

Financial support and sponsorship

Nil.

\section{Conflicts of interest}

There are no conflicts of interest.

\section{Jagannath Dev Sharma', Debanwita Mahanta', Anupam Sarma', Shiraj Ahmed', Lopamudra Kakoti', Amal Chandra Kataki ${ }^{2}$}

Departments of ${ }^{1}$ Pathology and ${ }^{2}$ Gynaecologic Oncology, Dr. B. Borooah Cancer Institute, Guwahati, Assam, India

Address for correspondence: Dr. Debanwita Mahanta, Department of Pathology, Dr. B. Borooah Cancer Institute, Gopinath Nagar, Guwahati - 781 016, Assam, India. E-mail:mdebanwita@yahoo.com

Submitted: 07-Jun-2018 Revised: 20-Jun-2019

Accepted: 12-Jul-2019

Published: 17-Feb-2020

\section{References}

1. Huh J. Epidemiologic overview of malignant lymphoma. Korean J Hematol 2012;47:92-104.

2. Boffetta P. Epidemiology of adult NHL. Ann Oncology 2011;22:iv27-31.

3. Ioachim HL, Medeiros LJ, editors. Nomenclature and classification of lymphomas. In: Ioachim's Lymph Node Pathology. $4^{\text {th }}$ ed. Philadelphia, PA: JB Lippincott; 2008. p. 301.

4. Naresh KN, Srinivas V, Soman CS. Distribution of various subtypes of non-Hodgkin's lymphoma in India: A study of 2773 lymphomas using R.E.A.L. And WHO classifications. Ann Oncol 2000;11 Suppl 1:63-7.

5. A clinical evaluation of the international lymphoma study group classification of non-Hodgkin's lymphoma. The non-Hodgkin's lymphoma classification project. Blood 1997;89:3909-18.

This is an open access journal, and articles are distributed under the terms of the Creative Commons Attribution-NonCommercial-ShareAlike 4.0 License, which allows others to remix, tweak, and build upon the work non-commercially, as long as appropriate credit is given and the new creations are licensed under the identical terms.

\begin{tabular}{|l|l|}
\hline \multicolumn{2}{|c|}{ Access this article online } \\
\hline Quick Response Code: & Website: \\
& www.ijmpo.org \\
\cline { 2 - 2 } & DOI: \\
\hline
\end{tabular}

How to cite this article: Sharma JD, Mahanta D, Sarma A, Ahmed S, Kakoti L, Kataki AC. Pattern of non-hodgkin lymphoma in a tertiary care center in Northeast India using morphology and immunohistochemistry. Indian J Med Paediatr Oncol 2019;40:595-7.

(c) 2020 Indian Journal of Medical and Paediatric Oncology | Published by Wolters Kluwer - Medknow 